\title{
ДИСКУССИИ
}

DOI: https://doi.org/10.15688/jvolsu2.2021.4.13

UDC 81'22



LBC 81.002

Submitted: 11.01 .2021

Accepted: 11.05.2021

\section{CONTINUALITY OF LANGUAGE LEVELS HIERARCHY}

\author{
Vladimir M. Savitsky \\ Samara State University of Social Sciences and Education, Samara, Russia
}

\begin{abstract}
The author points out that the structure of language levels system is still a crucial linguistic problem, that research in this field is far from being completed and that there is a need for further improvement of the current models of language levels hierarchy. The author sets out his reflections that sprang up from striving to eliminate some contradictions in the existing models of the language levels system. Applying the method of comparative analysis, elements of the model theory and linguistic systemology, using the Russian language material supplemented by some sporadic examples from other languages, the researcher puts forward a number of amendments to the existing models of the language levels hierarchy - amendments intended for riddance of the above-mentioned contradictions. The author argues in favor of merging the morphological and lexical levels, as well as the level of syntax and that of utterances, and offers insertion of the word combinations level at which language units and speech units co-exist, forming two intersecting sub-levels. The expediency of combining the system of language levels and that of speech levels into a common speech-language space has been proved. Using the empirical material, the author demonstrates the level boundaries blurring and existence of inter-level gaps, which contain hybrid units that have typological features of both the upper level and the lower level. The following conclusion is drawn: the speech-language hierarchy must be schematically presented not so much a column of hard and fast lines as a linguistic continuum with smooth transitions between the levels. phrases.

Key words: language system level, linguistic continuum, hierarchy of levels, language unit stability, free

Citation. Savitsky V.M. Continuality of Language Levels Hierarchy. Vestnik Volgogradskogo gosudarstvennogo universiteta. Seriya 2. Yazykoznanie [Science Journal of Volgograd State University. Linguistics], 2021, vol. 20, no. 4, pp. 158-169. (in Russian). DOI: https://doi.org/10.15688/jvolsu2.2021.4.13
\end{abstract}

\section{КОНТИНУАЛЬНЫЙ ХАРАКТЕР ИЕРАРХИИ ЯЗЫКОВЫХ УРОВНЕЙ}

\section{Владимир Михайлович Савицкий}

Самарский государственный социально-педагогический университет, г. Самара, Россия

\footnotetext{
Аннотация. В статье показано, что строение системы языковых уровней остается важной лингвистической проблемой и что исследования в данной области еще далеко не завершены. Обоснована необходимость дальнейшего совершенствования имеющихся моделей иерархии уровней языка. Используя метод сопоставительного анализа, элементы теории моделей и лингвистической системологии, изучая материал русского языка с привлечением отдельных примеров из других языков, автор предложил ряд уточнений к существующим моделям, нацеленных на устранение выявленных в результате анализа противоречий. В ста-
} 
тье выдвинуты аргументы в пользу объединения в модели морфологического и лексического уровней, а также уровней синтаксиса и высказывания. Предложено ввести уровень сочетаний слов, где языковые и речевые единицы сосуществуют, образуя два подуровня. Доказана целесообразность объединения систем языковых и речевых уровней в общее речеязыковое пространство. Автором продемонстрирована размытость границ между уровнями и существование межуровневых участков, которые содержат гибридные единицы, имеющие типологические признаки как единиц языка, так и единиц речи. Сделан вывод о том, что речеязыковая иерархия представляет собой лингвистический континуум с постепенными переходами между уровнями.

Ключевые слова: уровень системы языка, лингвистический континуум, иерархия уровней, устойчивость языковых единиц, переменные сочетания слов.

Цитирование. Савицкий В. М. Континуальный характер иерархии языковых уровней // Вестник Волгоградского государственного университета. Серия 2, Языкознание. - 2021. - Т. 20, № 4. - C. 158-169. - DOI: https://doi.org/10.15688/jvolsu2.2021.4.13

\section{Введение}

Вопрос о том, как устроена иерархия уровней языковой системы, до сих пор остается одним из фундаментальных в лингвистике. Усилия, направленные на его решение, можно охарактеризовать известным выражением quest for the essence of language (поиски сущности языка) [Jakobson, 2012, p. 413]. Не зря среди языковедов бытует мнение, пусть и утрированное, но нелишенное некоторых оснований: кто наконец сконструирует непротиворечивую модель уровней языковой системы, тот разработает полную теорию строения языка.

На тему языковых уровней существует обширная литература (ее обзор см., в частности, в: [Бижоев, 2014]), но изыскания, проводимые в данном направлении, далеки от завершения. Каждый лингвист, который обращается к этому вопросу, вносит в его разработку посильный вклад. Ниже приводятся наши соображения, родившиеся из стремления устранить некоторые противоречия в имеющихся моделях системы языковых уровней.

Чем вызвана необходимость многоуровневости языка?

Чтобы выразить несколько десятков концептов, которыми ограничивался кругозор первобытного человека в далекие доисторические времена, вероятно, хватало одно- или двухуровневой знаковой системы, однако, как будет показано ниже, чтобы язык мог десигнировать сотни тысяч концептов высокоразвитой лингвокультуры, требуется значительно большее число уровней. Это вызвано необходимостью достичь баланса синтагматики и парадигматики, без которого невозможно вы- ражать огромное количество концептов и при этом оставаться в границах психофизических возможностей человека.

\section{Материал и методы}

Для выявления противоречий в существующих моделях организации языковых уровней и поиска путей их совершенствования используются метод сопоставительного анализа, элементы теории моделей и лингвистической системологии; исследуется материал русского языка с привлечением отдельных примеров из других языков.

\section{Результаты и обсуждение}

С целью подтверждения этого тезиса о необходимости баланса синтагматики и парадигматики в организации языковых уровней проведем мысленный эксперимент на основе идей математической комбинаторики. Вообразим двухуровневую знаковую систему; на нижнем уровне системы располагаются элементарные единицы (например, фонемы), а на верхнем - производные единицы, которые представляют собой синтагмы элементарных единиц (фонем). Если парадигма фонем малочисленна, то, чтобы выразить огромное число концептов, синтагмы придется делать столь длинными, что с ними не справится человеческая память. При этом речевая цепь окажется непомерно растянутой, время общения станет очень долгим, а пропускная способность канала связи - небольшой. В целом эффективность общения будет далеко не достаточной для нужд современной цивилизации. 
Если же резко укоротить синтагмы, то придется создавать громадную парадигму элементарных единиц (фонем), с которыми не справится теперь уже артикуляторный аппарат человека и его психический механизм распознавания фонем на слух. Однако даже если постараться уравновесить парадигматику и синтагматику, создав среднего размера парадигму исходных единиц и получив средней длины синтагмы, то все равно как парадигма, так и синтагмы будут содержать слишком большое число единиц. Фонемный фонд в 300-400 фонем и слова длиной в полсотни фонем можно охарактеризовать метким выражением лингвистический ад [Jespersen, 2017 , p. 119]. Ясно, что двухуровневая знаковая система в любом из вышеописанных вариантов непригодна для выполнения столь серьезной задачи, как выражение сотен тысяч концептов.

Чтобы знаковая система соответствовала природным возможностям человека и позволяла эффективно (то есть емко и лаконично) выражать мысль, она (и вместе с нею речевая цепь) должна быть многоуровневой. Этот принцип реализован в естественных языках. Путем комбинирования фонем создаются морфемы; путем комбинирования морфем - слова и т. д. В итоге из небольшого числа исходных единиц возникают достаточно короткие единицы лексического уровня: средняя длина знаменательного слова в японском языке составляет 10,8 фонем, в русском - 7,2, в английском 5,2 и т. д. [Левицкий В.В., 2012, с. 228]. Такое соотношение находится в границах человеческих возможностей и делает вербальную коммуникацию в достаточной степени эффективной. Принцип многоуровневости знаковой системы, в основе которого лежат закономерности математической комбинаторики, - великое достижение коллективного разума, обусловившее прогресс цивилизации и культуры.

Нижний уровень языка - фонологический. На нем располагаются фоны (звуки языка), объединенные в фонемы; как известно, по отношению к ним фоны выступают как позиционные варианты - аллофоны. Количество фонем в среднем по языкам составляет от 20 до 50 [Бурлакова и др., 1962, с. 14].
Выше располагается морфемный уровень, который содержит морфы - минимальные из языковых единиц, обладающих значением. Они объединены в морфемы; по отношению к морфемам морфы выступают как позиционные варианты - алломорфы. Морфемы представляют собой синтагмы фонем. Число единиц данного уровня в среднем по языкам составляет 3000-5000 (так, СМ включает около 5000 морфем). Это на два порядка (примерно в 100 раз) больше количества единиц нижнего уровня - фонем.

Многие языковеды следующим называют морфологический уровень - уровень словоформ. Принцип постулирования уровней здесь остается прежним: словоформы являются синтагмами морфем.

До сих пор все представляется логичным и последовательным, но если постулировать уровень словоформ, то далее общий принцип построения иерархии уровней окажется нарушенным, поскольку единицы следующего уровня - слова́ - складываются из словоформ не по синтагматическому, а по парадигматическому принципу. Как же устранить эту непоследовательность в постулировании уровней языка?

Когда слово рассматривается как комплекс вариантов, оно называется лексемой. Варианты лексем бывают разных видов. Лексема складывается:

- из морфологических вариантов (словоформ): судьба, судьбы, судьбе, судьбою, о судьбе (Б. Окуджава. Заезжий музыкант);

- лексико-семантических вариантов (носителей разных лексических значений): стол $^{1}$ (предмет мебели), стол ${ }^{2}$ (учреждение), стол $^{3}$ (питание; диета);

- фонетических вариантов: ноль / нуль;

- морфемных вариантов: волчиха / волчища;

- орфографических вариантов: каратэ / карате.

Думается, целесообразно поместить над морфемным уровнем не уровень словоформ, а уровень лексем; словоформы же, рассматриваемые как позиционные варианты лексем, называть аллолексами - подобно тому, как варианты фонем называются аллофонами, а варианты морфем - алломорфами. (Использование наименования аллолексы представля- 
ется логичным, хотя из-за неблагозвучия или по иной причине оно не прижилось в научном обиходе.)

В таком случае сохраняется общий принцип построения иерархии: всякая единица вышележащего уровня (лексема) являет собой синтагму единиц нижележащего уровня (морфем). Уровень словоформ (морфологический уровень) при этом не постулируется. Словоформы, будучи морфологическими вариантами лексем, включаются в состав лексем и относятся к лексическому уровню - так же, как фонетические и другие варианты лексем. Такова логика иерархии.

Здесь может возникнуть возражение: исследователь - это наблюдатель, а не творец языка, не дизайнер его устройства. Как он может «поместить один уровень выше другого» или «вместо другого», «ввести один уровень и убрать другой» и т. п.? Это непростой методологический вопрос, который касается характера соотношения объекта и его модели. Разумеется, лингвисты не перекраивают объективно существующую структуру языка. Они проделывают это не с языком, а с его моделями, которые они сами же и конструируют. Поскольку в терминах кибернетики система языка представляет собой «черный ящик» (объект, внутреннее строение которого недоступно прямому наблюдению), критериями адекватности модели объекту (оригиналу) считаются логическая непротиворечивость, сравнительная простота и объяснительная сила модели [Лебедев, 2018]. К этому идеалу и стремятся лингвисты, перестраивая и совершенствуя не язык, а созданные ими модели языковой структуры. Они «творят язык» в том же смысле, в котором физики «творят вселенные»: для краткости физики говорят о «вселенной Эйнштейна», «вселенной Фридмана», «вселенной Хокинга» и т. д., имея в виду модели строения Вселенной.

Словарный фонд развитых языков (полмиллиона и более слов) по числу единиц на два порядка $(\times 10 \times 10)$ превышает морфемный фонд. Как видим, в количественном отношении каждый шаг иерархии (как говорят математики, знаменатель геометрической прогрессии) составляет два порядка: морфем в $\approx 100$ раз больше, чем фонем, а слов в $\approx 100$ раз больше, чем морфем.
Какой уровень находится выше лексического? По этому вопросу мнения расходятся. Часть языковедов следующим считает синтаксический уровень. Но А.В. Кунин верно указал на то, что уровень синтаксиса не рядоположен другим уровням, так как на нем располагаются не единицы, а конструкции. А.В. Кунин полагал, что «фразеологический уровень является высшим языковым уровнем» [Кунин, 1970, с. 30]. Эти утверждения вызывают некоторые возражения. Во-первых, есть целый ряд раздельнооформленных единиц помимо фразеологизмов: фразеоматизмы, составные термины, клише, штампы и т. д. При таком подходе остается неясным, куда следует их отнести. Во-вторых, провозгласив наличие фразеологического уровня, исследователь будет вынужден признать, что это фрагментарный уровень, охватывающий отнюдь не все единицы более низкого уровня: как известно, фразеологизмы включают в свой состав лишь меньшую часть слов, образующих лексический фонд языка.

Самой логичной нам представляется следующая версия: над уровнем слов располагается уровень сочетаний слов. Они являются синтагмами слов. Таким образом, общий принцип построения иерархии соблюдается и здесь.

Эту версию мы выносим на обсуждение. Контраргумент против нее состоит в том, что сочетания слов в своем большинстве относятся не к системе языка, а к речевой стихии. Это неустойчивые (переменные) сочетания; они не воспроизводятся как готовые единицы, а производятся в речи вновь и вновь. Они действительно речевые, однако, на наш взгляд, отсюда следует не то, что уровня сочетаний слов не существует, а то, что данный уровень относится частично к языку, а частично к речи. Это - речеязыковой уровень, место смыкания корпуса единиц языка и корпуса единиц речи, на котором совместно (на двух подуровнях) расположены языковые единицы (устойчивые сочетания слов) и речевые единицы (переменные сочетания слов). При этом на границе подуровней имеет место взаимная диффузия этих корпусов единиц (о нише, которую на этом уровне занимает фразеологический фонд языка, см. в: [Савицкий, 1993]). 
Нам могут возразить: дихотомия «язык :: речь» постулируется по парам дифференциальных признаков «виртуальное:: реальное» и «ненаблюдаемое :: наблюдаемое». Иными словами, язык размещается в головах коммуникантов, а речь существует объективно-реально, она слышна и видна. Как можно провести границу между онтологически разнородными явлениями?

На это у нас есть ответ: дихотомия «язык :: речь» может быть постулирована не только по указанным парам, но и по паре дифференциальных признаков «устойчивое :: неустойчивое». Устойчивые (языковые) единицы - фонемы, морфемы, слова, фразеологизмы, фразеоматизмы, паремии и др. - столь же объективно-реальны, сколь и неустойчивые (речевые) единицы - переменные сочетания слов и переменные высказывания. Проводя с этих позиций границу между языком и речью, мы имеем в виду онтологически однородные явления: корпус языковых (устойчивых) единиц и корпус речевых (неустойчивых) единиц.

Учитывая, что устойчивость единиц является градуальной величиной (подтверждение этого см. в: [Савицкий, Кулаева, 2004]), можно, по нашему мнению, утверждать, что на уровне сочетаний слов сосуществуют высокоустойчивые, среднеустойчивые, слабоустойчивые, а также неустойчивые единицы. Четко подразделить их на подуровни весьма трудно. Граница между корпусом языковых (устойчивых) и корпусом речевых (переменных) единиц размыта в широком диапазоне.

Точнее говоря, эта граница размыта более чем на одном уровне иерархии. Промежуточная зона охватывает уровни слов, сочетаний слов и высказываний; языковые и речевые единицы на них представлены в разных пропорциях.

На лексическом уровне устойчивых единиц подавляющее большинство, но все же там имеются и слабоустойчивые, и неустойчивые слова. Среди них:

- поэтические и юмористические авторские окказионализмы: мир тиховейных слов (К. Бальмонт), стая легких времирей (В. Хлебников), кобелировать / кобеляж (И. Ильф и Е. Петров), недоперевыполнить (М. Зощенко);
- случаи языковой игры: сюрпризрак < сюрприз + призрак (А. Вознесенский), врачебный конвульсиум < консилиум + конвульсии (М. Жванецкий);

- перлы детского словотворчества: намакаронился "наелся макарон», мазелин < мазь + вазелин (К. Чуковский);

- конструируемые в обыденной речи слова со свободно присоединяемыми аффиксами: супермозг, супергерой, суперкайф; санкционка, удалёнка и др.;

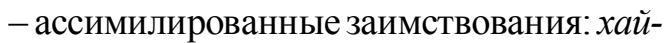
пить, майнить, лайфхачить и др.;

- неустойчивые сложные слова: растяжечно-силовые упражнения, кефирно-яблочная диета, шорто-футболочная комбинация и др.;

- иные случаи окказиональной реализации потенциала словообразовательных моделей, удовлетворяющей ситуативно обусловленные потребности номинации (в частности, дериваты онимов: асса́нжевские разоблачения «разоблачения, сделанные Дж. Ассанжем», ике́евские товары «товары торговой сети IKEA» и др.).

В процессе вербальной коммуникации регулярно порождаются слова, среди которых многие так и остаются речевыми, не достигнув той степени устойчивости, которая требуется для вхождения слов в систему языка.

Что касается уровня высказываний, на нем тоже располагаются как речевые (переменные), так и языковые (устойчивые) единицы - пословицы, поговорки, клише и др. Таким образом, «буферная» зона между языком и речью охватывает три уровня речеязыковой иерархии.

Высказывания имеют форму грамматического предложения и образуют свой собственный уровень. Мы не называем его ни уровнем предложений, ни синтаксическим уровнем по той причине, которая упоминалась нами выше: синтаксис, содержащий конструкции, не рядоположен уровням, содержащим единицы. «Предложение... единица формальная, грамматическая. Реальной коммуникативной единицей выступает высказывание» [Левицкий Ю.А., 1999, с. 99]. На наш взгляд, систему синтаксических конструкций нецелесообразно считать уровнем языка. Эти конструкции встроены в высказывания, состав- 
ляя их реляционный каркас. Поэтому мы рассматриваем их как ингерентную часть высказываний и не постулируем отдельный синтаксический уровень.

Уровень высказываний имеет главным образом речевой характер. В подавляющем большинстве высказывания являются переменными. Как правило, высказывание - это синтагма из двух и более сочетаний слов; встречаются, впрочем, и высказывания, содержащие только одно сочетание слов $(\mathrm{Om}$ дать швартовы!!) и даже одно слово (Ухо$\partial u$ ). Количество высказываний (как и число сочетаний слов) настолько велико, что не поддается точному учету.

Если по-прежнему исходить из того, что каждый шаг иерархии составляет два порядка (знаменатель прогрессии $\approx 100$ ), то общее количество сочетаний слов (устойчивых и переменных) исчисляется сотнями миллионов, а количество высказываний - десятками миллиардов. (Мы имеем в виду не только единицы, реально наблюдаемые в речи, но и те, которые могут быть созданы по правилам языка и предписаниям нормы речи.) Как видим, потенциал языка огромен.

На самом верху речеязыковой иерархии расположен уровень текста. На нем тоже соблюден общий принцип построения иерархии: текст представляет собой синтагму высказываний. Этот уровень относится исключительно к речи: не бывает текстов, являющихся единицами языковой системы.

Итак, взаимопереход «язык $\leftrightarrow$ речь» характеризуется постепенностью. Это побуждает нас к тому, чтобы постулировать общее речеязыковое пространство (лингвистический континуум) с единой иерархией уровней (о концепции лингвистического континуума см.: [Савицкий, Кулаева, 2004]).

Ниже приводится соответствующий нашим представлениям перечень уровней речеязыкового пространства с указанием приблизительной пропорции речевых и языковых единиц на каждом уровне: чевой );

- уровень текстов (исключительно ре-

- уровень высказываний (преимущественно речевой);

- уровень сочетаний слов (как речевой, так и языковой); ковой);

- уровень слов (преимущественно языковой);

- уровень морфем (исключительно языковой).

- уровень фонем (исключительно язы-

Не во всех случаях единица вышележащего уровня является синтагмой единиц предшествующего уровня. Одночленное множество - частный случай множества. В отдельных случаях единица, принадлежащая к более высокому уровню, состоит лишь из одной единицы нижележащего уровня. Встречаются:

- морфемы, которые состоят лишь из одной фонемы (6-, -bl);

- слова, которые состоят лишь из одной морфемы (вот, так);

- высказывания, состоящие из одного слова (Зима. Вечереет).

Единица более низкого уровня может пройти сквозь несколько высших уровней. Встречаются словоформы и слова, состоящие из одной фонемы, и высказывания из одной словоформы, которая состоит лишь из одной фонемы. Удачная иллюстрация этого факта содержится в известной древнеримской притче. Два сенатора заключили пари, кто сможет выразиться лапидарнее. Первый сказал: Eo rus (лат. «Уезжаю в село»), полагая, что короче сказать невозможно. Второй ответил: I (лат. «Поезжай») [Meynet, 1998, p. 247]. Он победил в этом состязании: в данном случае единица $I$ представляет собой фонему, морфему, слово (глагол ire «ехать / идти» в императивной форме единственного числа), высказывание (реплику).

Использование одной единицы вместо синтагмы единиц - это проявление закона языковой экономии: оно способствует сокращению речевой цепочки, речевых усилий и времени коммуникации, повышает пропускную способность канала связи.

Вышеописанная модель речеязыковой иерархии является структурной. М.В. Никитин предложил иную, а именно функциональную модель, коррелирующую со структурной моделью. Исходя из функций единиц языка и речи, он выделил:

- уровень дистинкторов, различающих смысл; 
- уровень фиксаторов, несущих смысл;

- уровень номинаторов, называющих объекты (предметы и явления);

- уровень коммуникаторов, сообщающих (передающих) смысл [Никитин, 1983].

В функции дистинкторов выступают в основном фонемы, в функции фиксаторов, как правило, морфемы, в функции номинаторов главным образом слова и сочетания слов, в функции коммуникаторов - по преимуществу высказывания. При этом единицы высших уровней сохраняют функции единиц низших уровней. Например, лексические компоненты сочетаний слов обычно бывают номинаторами, однако при этом они остаются и фиксаторами, и дистинкторами, например: дать леща («ударить») - дать маху («просчитаться») дать дёру («убежать») и т. п.

Соотношение функциональных и структурных уровней речеязыковой иерархии не является изоморфным, то есть взаимно-однозначным соответствием. Если единица перестала выполнять свою основную функцию, то она выполняет функцию предыдущего уровня иерархии. Так, в основной роли дистинкторов в ряде случаев выступают не фонемы, а морфемы, если они утратили функцию фиксаторов. Например, в словах брусника, карика, куманика формант -ика означает «ягода», а корневые морфемы потеряли самостоятельные значения и в наше время выполняют «лишь функции, подобные тем, которые выполняют фонемы в составе слова» [Телия, 1969, с. 211]. Эти корневые морфемы - не фиксаторы, а только дистинкторы, которые позволяют различать значения этих названий ягод, и не более того.

Аналогичным образом слова порой теряют функцию номинаторов; у них остается лишь функция фиксаторов. В этом отношении такие слова сближаются с морфемами. Приведем примеры: штык-нож, штаб-кварти$p a$, генерал-майор. Компоненты этих языковых единиц не склоняются и имеют только признаки морфем-фиксаторов. Падежные флексии принадлежат не второму компоненту, а всему слову целиком: (штык-нож) $a$, (штык-нож)у и т. д.

Более того, слово порой утрачивает статус не только номинатора, но и фиксатора, сохранив лишь статус дистинктора и уподоб- ляясь в этом отношении фонеме. Таков, например, лексический компонент баклуши во фразеологизме бить баклуши: он не обладает самостоятельным значением и выполняет только смыслоразличительную функцию (бить баклуши :: бить поклоны).

Существуют высказывания, переставшие быть коммуникаторами и выполняющие только функцию номинаторов, уподобляясь в этом отношении словам. Приведем ряд примеров.

(1) Разве Валька простила бы его шуры-муры с этой, как ее... - Дуся посмотрела на стушевавшегося Леонида с надеждой, что он подскажет ей, как звали эту «прости Господи» (Аксенов, с. 22).

Здесь высказывание прости Господи функционирует как слово - в номинативной функции, в субстантивном значении «гулящая девица».

(2) Не буду молчать! У самих хлеба осталось кот наплакал, а ты его, чёрта горбатого, содержишь, кормишь каждый день (М.А. Шолохов. Тихий Дон // ФС).

Высказывание кот наплакал тоже выступает здесь как слово - в номинативной функции, в адвербиальном значении «очень мало».

(3) Понимаешь, в студии у них работка не бей лежачего, вот они и не хотят менять ее на мастерские (И.В. Коваленко. Откровения юного Слоева // ФС).

Здесь высказывание не бей лежачего употреблено как слово - в номинативной функции, в адъективном значении «легкая».

На сближении функций разноуровневых единиц основывается регрессия (спуск) некоторых из них на более низкий уровень иерархии, превращение сочетания слов или даже высказывания в сложное слово, а составляющих его слов - в морфемы, например: благо дарю $\rightarrow$ благодарю; с ума сшедший $\rightarrow$ сумасшедший; за благо рассудится $\rightarrow$ заблагорассудится; англ. also ran (букв. «тоже бежал») $\rightarrow$ an also-ran (сложное слово, которое означает «участник состязания, не занявший призового места»); фр. écoute s'il pleut (букв. «послушай, не идет ли дождь») $\rightarrow$ un écoute-s'il-pleut (сложное слово, имеющее два значения: 1. «Паникёр, пасующий даже перед небольшими трудностями». 2. «Туманное обещание»). 
В русском языке упомянутая регрессия затруднена вследствие большого количества флексий, которые препятствуют слиянию сочетаний слов в слова. Поэтому она чаще происходит с одновершинными сочетаниями слов: в миг $\rightarrow$ вмиг; на верху $\rightarrow$ наверху; изпод тишка (тишок устар. «подворотня») $\rightarrow$ исподтишка; не в домёк (домёк устар. «догадка, соображение») $\rightarrow$ невдомёк; не в моготу (могота устар. «сила, мощь») $\rightarrow$ невмоготу и т. п.

В английском же языке, с его относительно бедным фондом флексий и обилием непроизводных (корневых) слов, такая регрессия представляет собой распространенное явление, не исключая двухвершинных сочетаний слов. Например, сочетания двух имен существительных (субстантивные биномы) нередко объединяются в сложные слова по следующему образцу: shot «дробь» + gun «ружье» $\rightarrow$ shotgun «дробовое ружье, дробовик».

Этому процессу особенно способствует идиоматизация (возникновение семантической целостности). Слияние значений слов в плане содержания порой ведет к слиянию самих слов в плане выражения, например: pig «свинья» + tail «хвост» $\rightarrow$ техн. pigtail «гибкий проводник». Аналогичный процесс наблюдается и в сочетаниях слов типа «прилагательное + существительное»: red «красный» + еуе «глаз» $\rightarrow$ redeye «крепкое виски». Именно цельнооформленность дает возможность отличать идиоматичные единицы (например, bigwig «важная персона, большая шишка») от единиц с буквальным значением (big wig «большой парик»).

В промежутке между уровнем слов и уровнем сочетаний слов находятся единицы, имеющие типологические признаки как того, так и другого уровня, например: культурно значимый / культурно-значимый (оба орфографических варианта встречаются в письменной речи). Этому способствует двойственность финали -о: она может осмысливаться как наречное окончание или как соединительная гласная.

Некоторые такие пары лишены амбивалентности; они отчетливо различаются не только в плане выражения, но и в плане содержания. Например: долго играющий / долгоиграющий аудиодиск. Первый член этой пары имеет буквальное значение («диск, играющий в течение длительного времени»). Это сочетание слов. У второго члена пары значение не буквально, оно в некоторой степени идиоматизировано; это сложное слово, обозначающее диск заданного формата с определенными техническими характеристиками. В данном случае идиоматизация сочетания слов тоже обусловила его слияние в сложное слово, приведшее к его спуску на нижележащий уровень иерархии.

Единицы с двойственным языковым статусом можно назвать лексемо-фраземами, а их компоненты - морфемо-лексемами (помимо наших исследований, такой подход использован в работах наших учеников; см., например: [Молчкова, 2012; Доладова, 2016]).

Единицы, которые обладают признаками двух уровней, встречаются и в промежутке между уровнем морфем и уровнем лексем. Таковы, например, компоненты русской языковой единицы диван-кровать. Если расценивать ее как аппозитивное сочетание слов типа спутник-шпион (в косвенных падежах склоняются оба компонента: спутником-шпионом), то она должна склоняться как сочетание слов (диваномкроватью). В этом случае ее компоненты следует считать словами. Однако если считать диван-кровать сложным словом типа плащ-палатка (склоняется все слово: плащ-палаткой), то оно должно склоняться как слово (диван-кроватью), и тогда его компоненты следует считать морфемами. В речи встречаются оба варианта склонения, что говорит о промежуточном (межуровневом) статусе названной единицы и ее компонентов; перед нами лексемо-фразема, состоящая из морфемо-лексем.

Изредка встречаются единицы, которые обладают типологическими признаками и корневой морфемы, и фонемы. Так, в слове щзи элемент щ-, с одной стороны, является корневой морфемой (щ-ец̆ / щ-ам, уменьшит. Haлей-ка мне щ-еи, устар. Чую щ-аной дух). С другой стороны, элемент щ-, рассматриваемый изолированно, не осмысливается как фиксатор (носитель) значения «капустный суп» (то есть как корневая морфема) и выполняет лишь дистинктивную функцию, присущую фонемам (щи :: ли; щей :: бей; щам :: нам). 
По данным ЭС, слово щзи восходит к древнерус. съть «еда». Лексикализованная форма множественного числа съти́ обозначала сначала сытную еду из многих ингредиентов, а затем - в результате сужения значения - один из видов такой еды (суп из капусты и других овощей с мясом). Впоследствии произошло фонетическое стяжение: съти́ $\rightarrow$ сти $\rightarrow u т u \rightarrow$ щи. В итоге остаток щз- от корня съmb- перестал ощущаться как морфема, хотя объективно это морфема.

Такие промежуточные единицы можно назвать фонемо-морфемами. Это не морфонемы. По Н.С. Трубецкому, морфонема - это комплекс фонем, которые чередуются в составе морфемы (например, $[\kappa / 4]$ в корне слов рука / ручной [Лингвистический..., 1990]. Что касается фонемо-морфемы, это языковая единица, которая имеет типологические признаки как фонемы, так и морфемы и потому располагается между уровнем фонем и уровнем морфем.

В ряде работ [Бижоев, 2014; Завьялов, 2015; Слюсарева, 1969; и др.] рассматривается вопрос о промежуточных подуровнях языковой иерархии и о находящихся там единицах. В частности, Н.А. Слюсарева выделила подуровни морфонем, сервем (служебных слов) и фразем (раздельнооформленных единиц, имеющих целостные значения, как слова). Во всем этом, несомненно, есть рациональное зерно: все перечисленные единицы связаны как с верхним, так и с нижним уровнем иерархии. Однако связаны они по-разному и выделяются по разным критериям, что несколько нарушает общую логику иерархии. В нашей модели фонемо-морфемы, морфемо-лексемы, лексемо-фраземы выделяются по одному и тому же критерию: каждая из них имеет типологические признаки как верхнего, так и нижнего уровня.

Это подталкивает к выводу, что единицы языка и речи группируются не в классы (таксоны с непересекающимися объемами), а в типы (таксоны с пересекающимися объемами). По одним признакам единица может относиться к одному типу, а по другим признакам - к другому типу. Поэтому такого рода признаки и называются типологическими.

Итак, мы убеждаемся, что межуровневые границы в языковой иерархии очер- чены не резко. «В действительности вообще нет никаких строго проведенных межей и граней, к великой горести всех систематиков» [Герцен, 1986, с. 225]. На наш взгляд, схематическому изображению иерархии уровней в виде столбца резких горизонтальных линий следует предпочесть изображение в виде радужного спектра, где цветовые слои диффузно проникают друг в друга, символизируя непрерывность взаимоперехода. Континуум радужного спектра модель континуума речеязыкового пространства.

\section{Выводы}

Модель иерархии уровней продолжает совершенствоваться. Резюмируя вышесказанное, перечислим предложения по структурированию языковых уровней, которые проистекают из наших представлений о структуре обсуждаемой иерархии:

- расценивать оптимальный баланс синтагматики и парадигматики в языке как основной фактор и основополагающий принцип построения иерархии уровней;

- рассматривать рост численности единиц на каждом последующем уровне иерархии как геометрическую прогрессию со знаменателем примерно 100;

- постулируя уровни, не отступать от правила, по которому единица более высокого уровня должна являться синтагмой единиц более низкого уровня;

- вследствие этого упразднить морфологический уровень, включив словоформы в состав лексем как их позиционные варианты, и синтаксический уровень, включив синтаксические конструкции в состав высказываний как их каркасы;

- постулировать уровень сочетаний слов, делимый на подуровень устойчивых единиц и подуровень переменных единиц с размытой границей между ними;

- соединить системы уровней языка и уровней речи в единую иерархию, в которой уровень сочетаний слов является «буферным»;

- принять во внимание размытость межуровневых границ, приводящую к тому, что речеязыковое пространство являет собой не вер- 
тикаль резко разделенных уровней, а лингвистический континуум;

- в межуровневых промежутках выявить «гибридные» единицы, обладающие типологическими признаками как выше-, так и нижележащего уровня;

- признать категорию «единица» (языка /

речи) типом, а не классом.

Осуществление перечисленных процедур в процессе структурирования иерархии языковых уровней может стать шагом на пути создания непротиворечивой, простой, имеющей объяснительную силу (то есть адекватность) модели языковой и речевой иерархии.

\section{СПИСОК ЛИТЕРАТУРЫ}

Бижоев Б. Ч., 2014. Об уровнях языковой системы // Армия и общество : науч.- информ. журн. Вып. 6 (43). С. 69-74.

Бурлакова М. И., Николаева Т. Н., Сегал Д. М., Топоров В. Н., 1962. Структурная типология и славянское языкознание // Структурно-типологические исследования : сб. ст. М. : AH CCCP. C. 3-18.

Герцен А. И., 1986. Письма об изучении природы // Герцен А. И. Сочинения. В 2 т. Т. 2. М. : Мысль. С. 220-398.

Доладова О. В., 2016. Проблема уровней языковой иерархии // Вестник Самарского университета. История. Педагогика. Филология. № 4. C. $105-112$.

Завьялов В. Н., 2015. О содержательных составляющих понятия «структура русских союзов» // Вестник Новосибирского государственного университета. Серия: История, филология. Т. 14, вып. 9. С. 85-90.

Кунин А. В., 1970. Английская фразеология (теоретический курс). М. : Высш. шк. 342 с.

Лебедев С. А., 2018. Проблема истинности научной теории // Гуманитарный вестник. № 4. C. 514-520.

Левицкий В. В., 2012. Семантический объем и длина слова // Левицкий В. В. Семасиология. Винница : Нова книга. С. 228-229.

Левицкий Ю. А.,1999. Язык, речь, текст. Пермь : Перм. гос. ун-т. 124 с.

Лингвистический энциклопедический словарь, 1990 / под ред. В. Н. Ярцевой. М. : Сов. энцикл. 688 с.

Молчкова Л. В., 2012. Иерархия уровней языка в свете концепции идиоматических кодов // Beстник Новосибирского государственного университета. Лингвистика и межкультурная коммуникация. Т. 10, вып. 2. С. 11-20.
Никитин М. В., 1983. Лексическоезначение слова (структура и комбинаторика). М. : Высш. шк. 124 с.

Савицкий В. М., 1993. Существует ли фразеологический уровень языка? // Савицкий В. М. Аспекты теории фразообразовательных моделей. Самара : Самар. гос. пед. ин-т. С. 60-65.

Савицкий В. М., Кулаева О. А., 2004. Концепция лингвистического континуума. Самара : Науч.техн. центр. $177 \mathrm{c}$.

Слюсарева Н. А., 1969. О некоторых проблемах иерархической организации языка // Единицы разных уровней грамматического строя и их взаимодействие : сб. науч. тр. / под ред. Н. Ю. Шведовой. М. : Наука. С. 269-273.

Телия В. Н., 1969. О вариантах протяженности идиом // Система и уровни языка : сб. науч. тр. / под ред. Э. А. Макаева. М. : Наука. С. 198-211.

Jakobson R., 2012. Quest for the Essence of Language // Jakobson R. Language in Literature. Harvard : University Press. P. 413-427. (Reprint).

Jespersen O., 2017. Mankind, Nation and Individualfrom a Linguistic Point of View. Oxbridge : Braithwaite Press. 221 p.

Meynet R., 1998. Rhetorical Analysis. Sheffield : Academic Press. 390 p.

\section{ИСТОЧНИКИ И СЛОВАРИ}

Аксенов - Аксенов М. Б. Сезон отпусков. М. : ЛитPec, 2018. $82 \mathrm{c}$.

$C M$ - Ефремова Т. Ф., Кузнецова А. И. Словарь морфем русского языка. М. : Рус. яз., 1986. 1135 с.

$\Phi C-$ Федоров А. И. Фразеологический словарь русского литературного языка. М. : Астрель : ACT, 2008. 878 c.

ЭС - Фасмер М. Этимологический словарь русского языка. В 4 т. Т. 4. М. : Астрель : АСТ, 2004. 860 c.

\section{REFERENCES}

Bizhoyev B.Ch., 2014. Ob urovnyakh yazykovoy sistemy [On Language System Levels]. Armiya i obshchestvo: nauch.-inform. zhurn., iss. 6 (43), pp. 69-74.

Burlakova M.I., Nikolayeva T.N., Segal D.M., Toporov V.N., 1962. Strukturnaya tipologiya i slavyanskoe yazykoznaniye [Structural Typology and Slavistics]. Strukturnotipologicheskiye issledovaniya: sb. st. [Explorations in Structural Typology. Collection of Articles]. Moscow, AN SSSR, pp. 3-18.

Herzen A.I., 1986. Pisma ob izuchenii prirody [Letters on Nature Exploration]. Herzen A.I. Sochineniya. 
$V 2$ t. T. 2 [Works. In 2 Vols. Vol. 2]. Moscow, Mysl Publ., pp. 220-398.

Doladova O.V., 2016. Problema urovney yazykovoy ierarkhii [Problem of the Levels of Language Hierarchy]. Vestnik Samarskogo universiteta. Istoriya. Pedagogika. Filologiya [Vestnik of Samara University. History, Pedagogics, Philology], no. 4, pp. 105-112.

Zavyalov V.N., 2015. O soderzhatelnyh sostavlyayushchikh ponyatiya «struktura russkikh soyuzov» [On Substantial Parts of the Concept "Structure" of Russian Conjunction]. Vestnik Novosibirskogo gosudarstvennogo universiteta. Seriya: Istoriya, filologiya [Vestnik NSU. Series: History and Philology], vol. 14, iss. 9, pp. 85-90.

Kunin A.V., 1970. Angliyskaya frazeologiya (teoretichesky kurs) [English Phraseology (Theoretical Course)]. Moscow, Vysshaya shkola Publ. $342 \mathrm{p}$.

Lebedev S.A., 2018. Problema istinnosti nauchnoy teorii [The Problem of Scientific Theory Truth]. Gumanitarny vestnik [Humanities Bulletin of BMSTU], no. 4, pp. 514-520.

Levitsky V.V., 2012. Semantichesky obyom i dlina slova [Semantic Volume and Length of a Word]. Levitsky V.V. Semasiologiya [Semasiology]. Vinnitsa, Nova kniga Publ., pp. 228-229.

Levitsky Yu.A., 1999. Yazyk, rech, tekst [Language, Speech, Text]. Perm, Permsky gosudarstvennyy universitet. $124 \mathrm{p}$.

Yartseva V.N., ed., 1990. Lingvistichesky entsiklopedichesky slovar [Encyclopedic Dictionary of Linguistics]. Moscow, Sovetskaya entsiklopediya Publ. 688 p.

Molchkova L.V., 2012. Ierarkhiya urovney yazyka v svete kontseptsii idiomaticheskikh kodov [Language Levels Hierarchy in Light of the Idiomatic Codes Theory]. Vestnik Novosibirskogo gosudarstvennogo universiteta. Lingvistika i mezhkulturnaya kommunikatsiya [Vestnik NSU. Series: Linguistics and Intercultural Communication], vol. 10, iss. 2, pp. 11-20.

Nikitin M.V., 1983. Leksicheskoye znacheniye slova (struktura i kombinatorika) [Lexical Meaning of a Word (Structure and Combinatorics)]. Moscow, Vysshaya shkola Publ. 124 p.

Savitsky V.M., 1993. Sushchestvuyet li frazeologichesky uroven yazyka? [Does the Phraseological Level of Language Exist?].
Savitsky V.M. Aspekty teorii frazoobrazovatelnykh modeley [Aspects of the Theory of Idiom-Formation Models]. Samara, Samarsky gosudarstvennyy pedagogichesky institut, pp. 60-65.

Savitsky V.M., Kulayeva O.A., 2004. Kontseptsiya lingvisticheskogo kontinuuma [Theory of Linguistic Continuum]. Samara, Nauchnotekhnichesky tsentr. $177 \mathrm{p}$.

Slyusareva N.A., 1969. O nekotorykh problemakh ierarkhicheskoy organizatsii yazyka [On Certain Problems of Hierarchical Structure of Language]. Shvedova N.Yu., ed. Yedinitsy raznykh urovney grammaticheskogo stroya i ikh vzaimodeistviye: sb. nauch. tr. [Units Belonging to Different Levels of Grammatical Structure and Their Interaction. Collection of Scientific Papers]. Moscow, Nauka Publ., pp. 269-273.

Teliya V.N., 1969. O variantakh protyazhonnosti idiom [On Variants of Idiom Length]. Makayev E.A., ed. Sistema i urovni yazyka: sb. nauch. tr. [System and Levels of Language. Collection of Scientific Papers]. Moscow, Nauka Publ. pp. 198-211.

Jakobson R., 2012. Quest for the Essence of Language. Jakobson R. Language in Literature. Harvard, University Press, pp. 413-427. (Reprint).

Jespersen O., 2017. Mankind, Nation and Individual From a Linguistic Point of View. Oxbridge, Braithwaite Press. $221 \mathrm{p}$.

Meynet R., 1998. Rhetorical Analysis. Sheffield, Academic Press. 390 p.

\section{SOURCES AND DICTIONARIES}

Aksyonov M.B. Sezon otpuskov [Holiday Season]. Moscow, LitRes Publ., 2018. 82 p.

Yefremova T.F., Kuznetsova A.I. Slovar morfem russkogo yazyka [Dictionary of the Russian Language Morphemes]. Moscow, Russky yazyk Publ., 1986.1135 p.

Fyodorov A.I. Frazeologichesky slovar russkogo literaturnogo yazyka [Phraseological Dictionary of Standard Russian]. Moscow, Astrel Publ., AST Publ., 2008. 878 p.

Fasmer M. Etimologichesky slovar russkogo yazyka. $V 4$ t. T. 4 [Etymological Dictionary of the Russian Language. In 4 Vols. Vol. 4]. Moscow, Astrel Publ., AST Publ., 2004. 860 p. 


\section{Information About the Author}

Vladimir M. Savitsky, Doctor of Sciences (Philology), Professor, Department of English Philology and Cross-Cultural Communication, Samara State University of Social Sciences and Education, Maxima Gorkogo St, 65/67, 443099 Samara, Russia, lampasha90@mail.ru, https://orcid.org/0000-0002-2277-925X

\section{Информация об авторе}

Владимир Михайлович Савицкий, доктор филологических наук, профессор кафедры английской филологии и межкультурной коммуникации, Самарский государственный социальнопедагогический университет, ул. Максима Горького, 65/67, 443099 г. Самара, Россия, lampasha90@mail.ru,https://orcid.org/0000-0002-2277-925X 